Research Article

Komal Chawla and Samit Ray-Chaudhuri*

\title{
A study on damping ratio of EPS foam filled CFRP composite tubes
}

https://doi.org/10.1515/cls-2020-0014

Received Nov 08, 2019; accepted Mar 12, 2020

\begin{abstract}
This study aims to investigate the damping behavior of the fundamental mode of a foam-filled carbon fibre reinforced polymer composite (CFRP) tube when subjected to base excitations. In particular, expanded polystyrene (EPS) foam balls (with negligible mass) of different sizes are used as fillers in the tube and the enhancement in damping ratio of the fundamental mode w.r.t the empty condition is evaluated for different intensity of base excitation. Shake table tests are performed on cantilever CFRP composite square hollow tube subjected to base excitation with varying amplitudes. The tube is filled with foam balls (of two different sizes) for varying depths of filling (no filling, one-third, two-third, and full). Accelerometers are mounted at different positions along the tube length and at the table to record the accelerations data for evaluation of damping ratio. From the recorded responses, frequency, mode shape and damping ratio of the fundamental mode are evaluated using a well-known approach. The damping ratio is noted to be around 1.41x (times) higher for the completely foam ball (bigger size) filled case under r.m.s base acceleration of $0.3 \mathrm{~g}$ when compared with the values corresponding to the empty case. The results suggest that the bigger foam balls enhance the damping ratio significantly without altering the natural frequency owing to additional energy dissipation in friction and impact generated through the sliding and collision of the balls while the tube is in motion.
\end{abstract}

Keywords: Woven CFRP tube, base excitation, foam balls, damping ratio

\footnotetext{
*Corresponding Author: Samit Ray-Chaudhuri: Department of Civil Engineering, Indian Institute of Technology Kanpur, UP 208016, India; Email: samitrc@iitk.ac.in

Komal Chawla: Department of Civil Engineering, Indian Institute of Technology Kanpur, UP - 208016, India
}

\section{Introduction}

One of the aspects that controls the dynamic response of any structure when subjected to an arbitrary dynamic loading is its damping properties. The damping properties in a structure play an important role towards the absorption of vibrational energy of the system and in turn help in suppressing the amplitude of vibration. For aeronautical and space structures, there is a need to enhance the inherent damping properties without increasing the weight of the system.

In recent years, there has been a growing attention in the research of thin walled fibre reinforced polymer (FRP) tubular structures. This is because, FRP composite is one of the favorable lightweight material owing to its extremely high strength to weight ratio and higher energy absorption capability as compared to conventional steel and aluminium materials [3]. Filling a tube with lightweight materials (such as aluminum honeycomb, metallic or polymer foam), is an approach for achieving higher strength while not increasing the mass. Moreover, such a filling significantly improves the capability of absorbtion and dissipation of vibrational energy.

Many studies were performed on metal and CFRP tubes, which were filled with different foams such as polyurethane foam $[4,5]$ and aluminum foam $[1-3,6,12$ 14]. Steel tubes filled with metal foams of open cell and close cell aluminum types were also investigated [1]. Experiments were performed and damping was evaluated using the parameter identification approach. Damping factor was found to be increased by almost five times in metal foam filled steel tube over an empty tube under high amplitude excitation. Later, the energy absorbtion efficiency of empty and foam filled steel and aluminum tubes was investigated under quasi-static and dynamic loading $[13,14]$. The tube was filled with ultralight pertile inclusions along with infiltration of molten aluminium to close the gaps between these inclusions by [13]. It was suggested that the filling of tube with foam/inclusions enhances the load bearing capacity and energy absorption efficiency $[13,14]$. The endurance capacity of aluminum foam filled steel and titanium tubes was analysed by performing cyclic three-point

๑ Open Access. (C 2020 K. Chawla and S. Ray-Chaudhuri, published by De Gruyter. 
bending tests [2]. The damping ratio of the tube was found to be increased due to hysteresis and frictional effects between the core and the inner tube surface. The inherent damping capability of additively fabricated alloy beam specimens was investigated by [15] using laser powder bed fusion (LPBF) under million cycles of high strain amplitude. The damping performance was found to be higher for beam with internal pockets containing unfused powder, which contributed in energy dissipation due to frictional effect generated by powder interactions.

EPS foam is one kind of a polymeric foam material, which is extremely lightweight. Besides, EPS foams have excellent strength to weight ratio and high energy dissipation efficiencies by [8-11]. To date, studies on dynamic response of lightweight EPS foam filled CFRP tubes are limited, in particular, the use the EPS foam inclusions as a filler in the tube to enhance the damping behavior. The aim of this work is to evaluate the damping ratio of the fundamental mode for empty and foam filled CFRP tubes under varying excitation amplitudes. To understand the influences of packing configuration on damping ratio, EPS foam balls of two different diameter $9 \mathrm{~mm}$ and $18 \mathrm{~mm}$ are used as a filler in the tube. Besides, to account for the movement of balls, the tube is filled $1 / 3^{\text {rd }}, 2 / 3^{\text {rd }}$ and completely. Accelerometers are attached at different locations along the tube height to record acceleration responses. Modal properties (natural frequency, mode shape and damping ratio of the fundamental mode) for the tubes with empty and foam filled states are then evaluated for varying levels of excitation.

\section{Experimental procedure}

Shake table experiments are performed on a woven CFRP square hollow tube having length, width and thickness of $1 \mathrm{~m}, 25 \mathrm{~mm}$ and $2 \mathrm{~mm}$, respectively. The tube is fabricated using epoxy consisting of HINPOXY C resin/HINPOXY C hardener (Bisphenol-A based liquid epoxy resin) having a mixing ratio of 100:30 (resin:hardner) and plain woven carbon fabrics with $200 \mathrm{GSM}$ (grams per square meter), provided by a commercial manufacturer (CFW Enterprises, www.cfw.enterprises.in). The tube is clamped to a small shake table (see Figure 1), driven by an electrodynamic shaker (http://www.dataphysics.com/). One accelerometer is mounted at the base of the tube to record the input base acceleration. The tube is instrumented with five miniature accelerometers (PCB Peizotronics, sensitivity $\approx 5$ $\mathrm{mV} / \mathrm{g}$ ), each weighing 35 grams including the perspex fixture, are used to measure various accelerations. For iden-

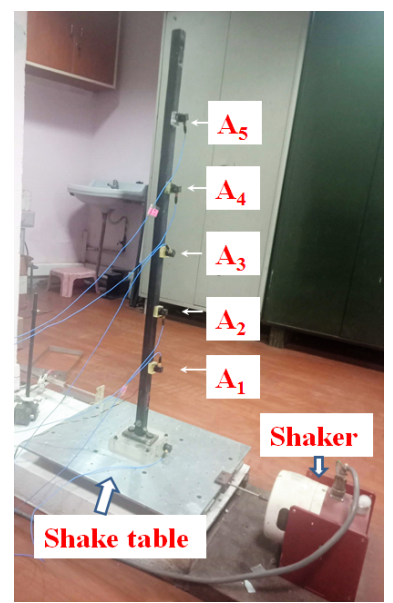

Figure 1: Experimental test set-up of CFRP composite square hollow tube

tification purpose, the accelerometers are marked from $A_{1}$ (near the base) to $A_{5}$ (top-most) as depicted in Figure 1. The accelerometers $\left(A_{1}-A_{5}\right)$ are located at height of $0.2 \mathrm{~m}-0.8 \mathrm{~m}$ with a gap of $0.15 \mathrm{~m}$ (with respect to the clamped end).

The shaker is excited with a band-limited white noise using a function generator (Keysight Technologies Agilent 33500B Series, Waveform Generator). The excitation level is controlled using a power amplifier (BAA $1000 \mathrm{https}: / /$ www.beak-electronic.de). The responses from the sensors are recorded using a data acquisition system (National Instrument, NI-DAQ PXIe-1062Q) and LabVIEW software (https://www.ni.com/).

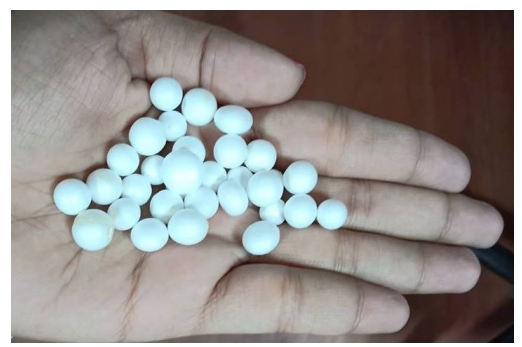

(a)

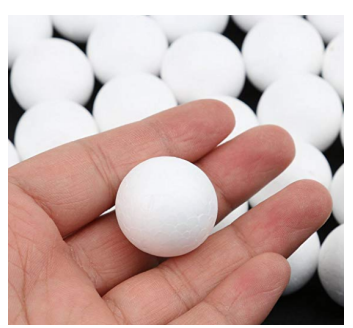

(b)

Figure 2: Expanded polystyrene foam balls: (a) $9 \mathrm{~mm}$ and (b) $18 \mathrm{~mm}$ diameter 


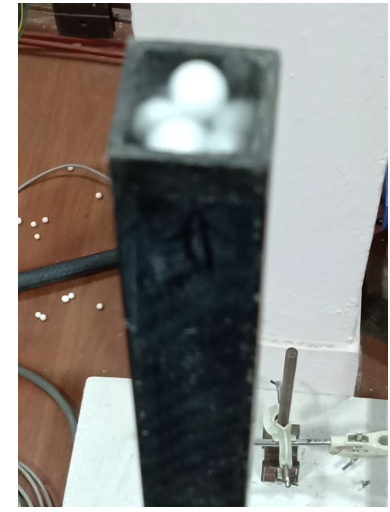

(a)

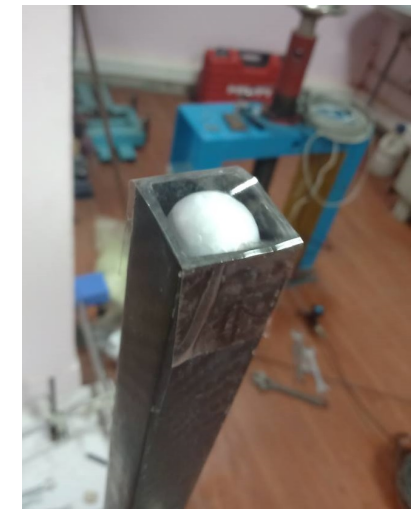

(b)

Figure 3: Top view of the tube filled with (a) $9 \mathrm{~mm}$ and (b) $18 \mathrm{~mm}$ diameter foam balls

EPS foam balls of $9 \mathrm{~mm}$ and $18 \mathrm{~mm}$ diameter are used to fill the tube as shown in Figures $2 \mathrm{a}$ and $2 \mathrm{~b}$, respectively. The tube is filled at one-third, two-third and full depth of the tube with these balls. The masses of $9 \mathrm{~mm}$ and $18 \mathrm{~mm}$ diameter balls in completely filled tube are measured as $3.3 \mathrm{gm}$ and $4.2 \mathrm{gm}$, respectively, which is quite less $(\sim 1 \%)$ in comparison to the total mass of the tube ( $400 \mathrm{gm})$. In completely filled state, the top of the tube is covered with scotch tape to avoid any spillover of the balls from the tube during the testing (as shown in Figure 3b).

\section{Free vibration and base excitation}

At first, free vibration tests are performed by imparting an initial excitation at the free end of the tube. Figure 4a shows the zoomed view of time history responses obtained from the accelerometers along the tube height. Figure $4 \mathrm{~b}$ shows the normalized Fourier amplitude spectra of accelerations obtained along the varying position along the tube height. One can note that the accelerometer near the top $\left(A_{5}\right)$ depicts the high amplitude as shown in Figure $4 \mathrm{~b}$. From the free vibration tests, the fundamental frequency of the tube can be noted around $18.67 \mathrm{~Hz}$.

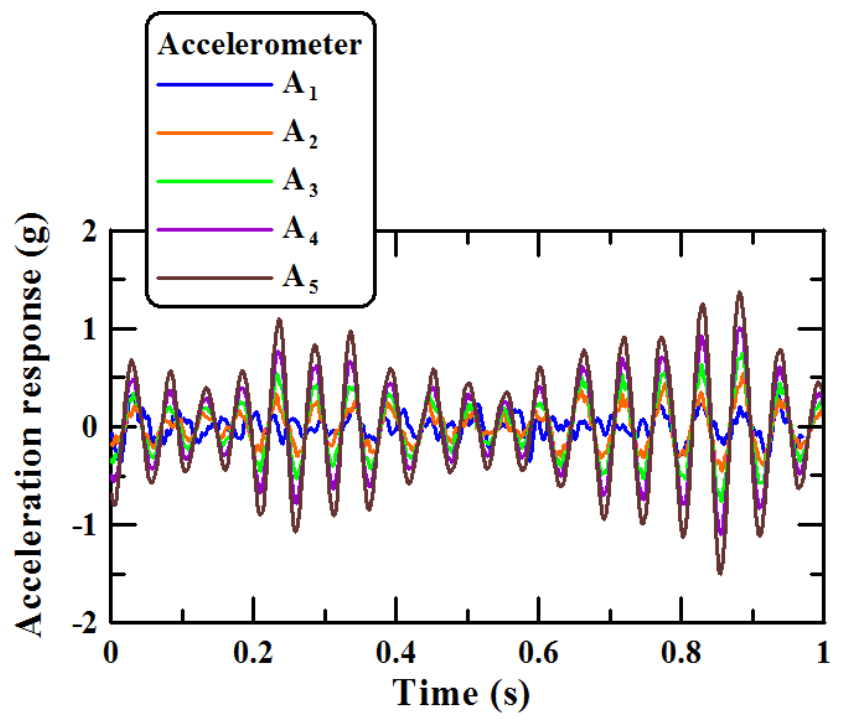

(a)

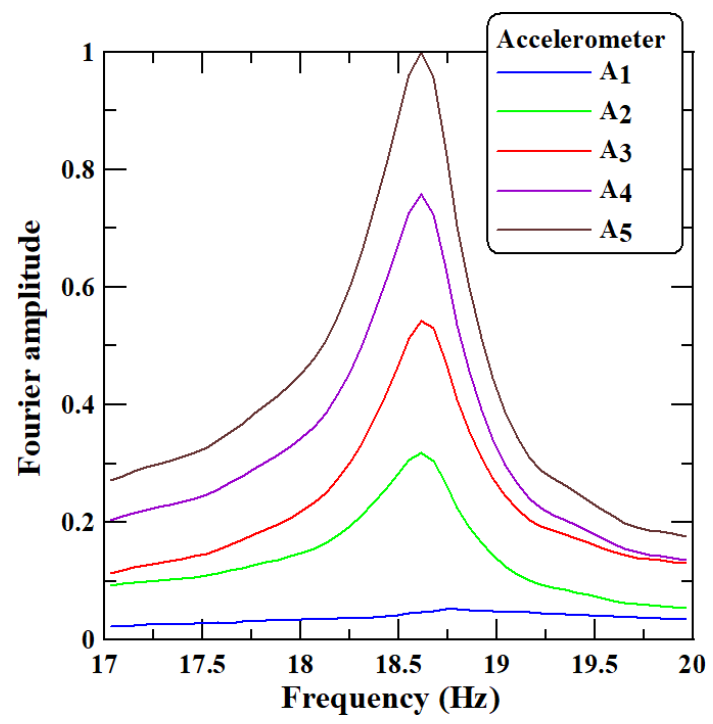

(b)

Figure 4: (a) Enlarged view of time history response and (b) normalized Fourier amplitude spectra 


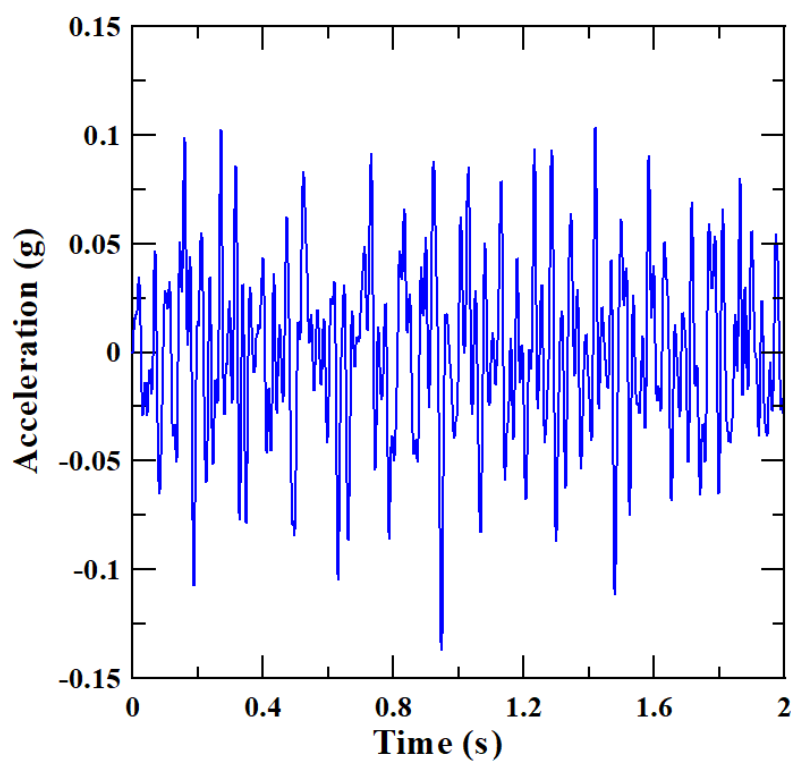

Figure 5: White noise signal from a trial

Further, the tube is subjected to base excitations with white noise of varying r.m.s amplitudes and having bandwidth of $10 \mathrm{~Hz}$ to $50 \mathrm{~Hz}$ for a time duration of $60 \mathrm{sec}$. Figure 5 shows the white noise signal with a r.m.s base acceleration amplitude around $0.039 \mathrm{~g}$ (measured using an accelerometer attached at the table).

\section{NExT-ERA approach}

The dynamic characteristics such as natural frequency, mode shape and damping ratio of the tube subjected to base excitation are evaluated using the NExT-ERA approach [16-19]. For this purpose, power spectral density (PSD) matrix is estimated from the acceleration data considering hanning window with a $50 \%$ overlap. Figure $6 \mathrm{a}$ shows the normalized power spectral density plot obtained from the recorded acceleration data at different positions along the tube height. The peaks in the PSD represent the fundamental frequency of the tube (i.e., around $18.81 \mathrm{~Hz}$ ). PSD matrix is further used to obtain the correlation matrix. Figures $6 \mathrm{~b}$ shows the autocorrelation function obtained from the acceleration data. The correlation matrix is then employed for evaluation of dynamic properties in the framework of ERA.

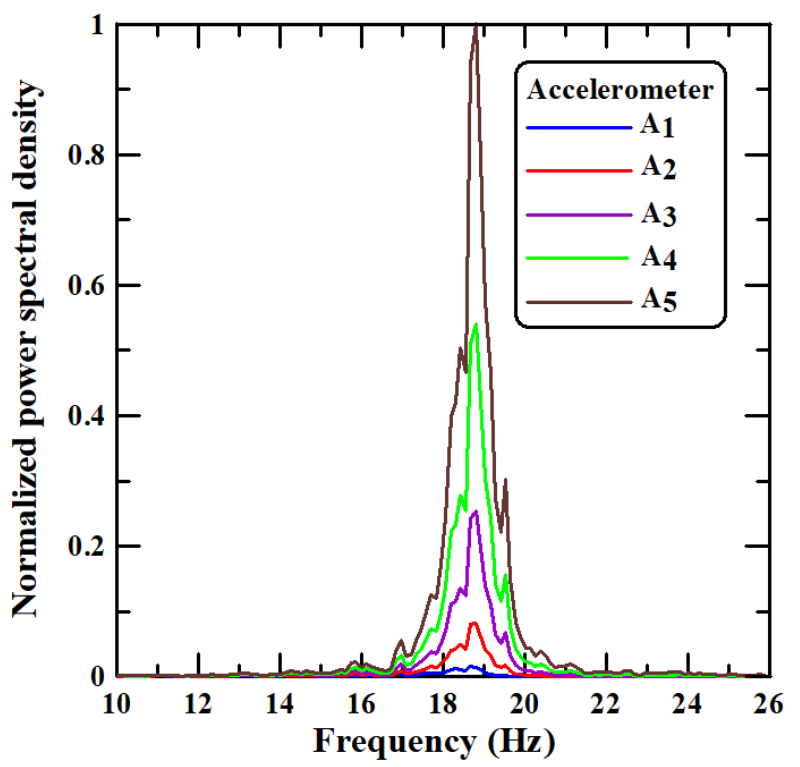

(a)

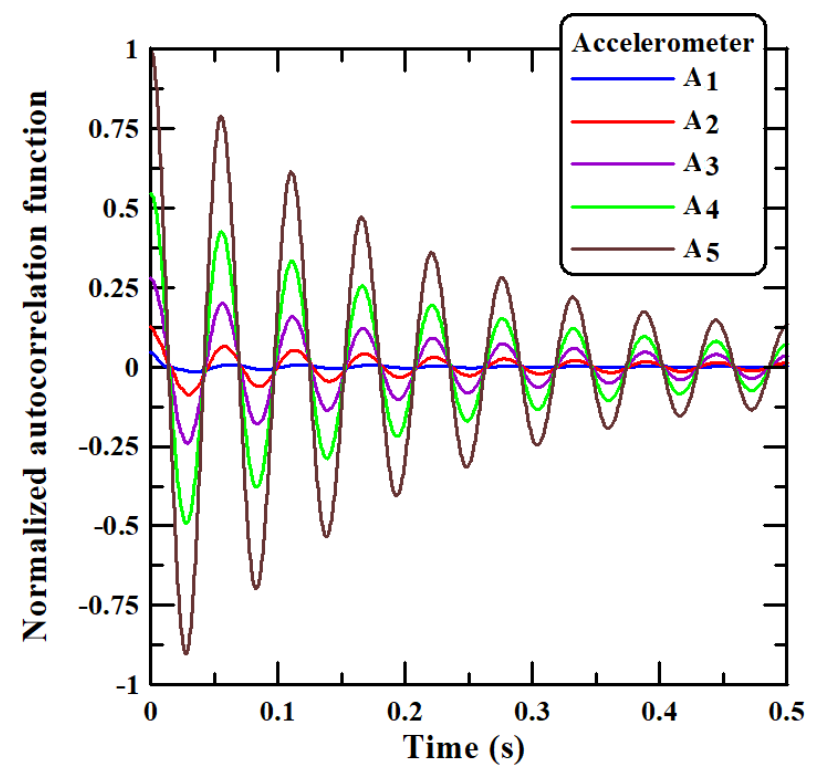

(b)

Figure 6: (a) Normalized power spectral density plot and (b) normalized autocorrelation function

\section{Fundamental frequency and mode shape}

From the NExT-ERA approach, the fundamental frequency and mode shape of the tube are obtained. Figures $7 \mathrm{a}$ and $7 \mathrm{~b}$ show the fundamental frequency of the tube in both empty and filled state with $9 \mathrm{~mm}$ and $18 \mathrm{~mm}$ diameter foam balls under varying levels of excitation, respectively. The points are fitted using least square approximation for clar- 


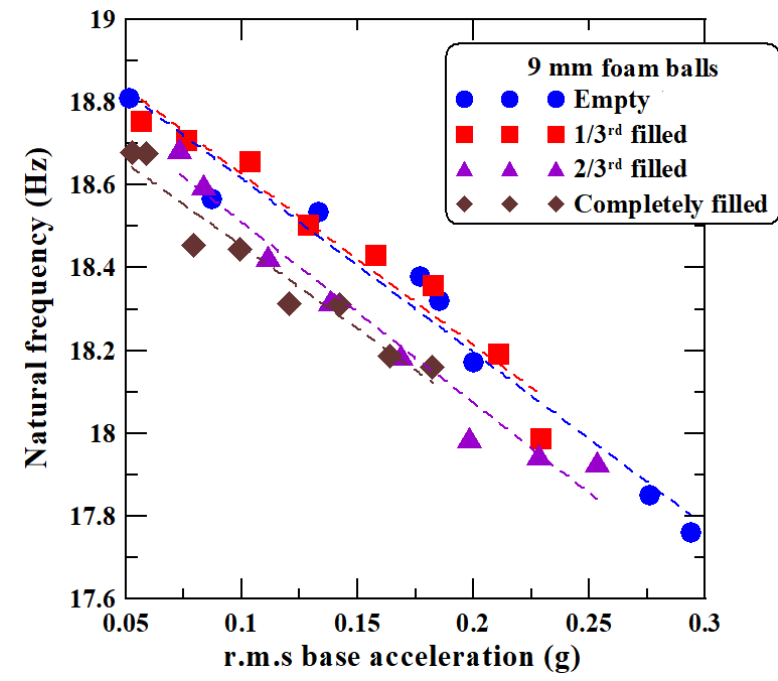

(a)

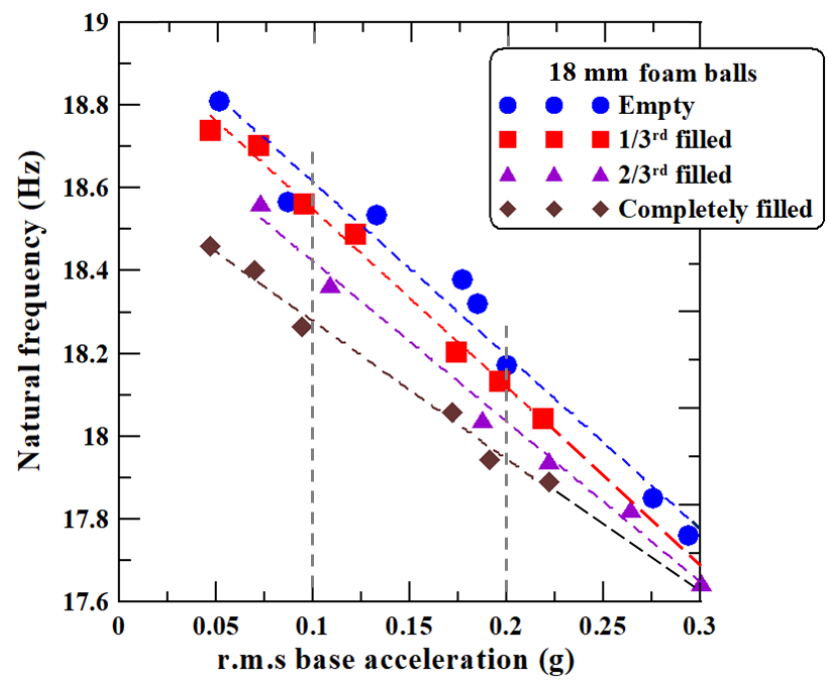

(b)

Figure 7: Fundamental frequency of foam filled tubes with: (a) $9 \mathrm{~mm}$ and (b) $18 \mathrm{~mm}$ diameter

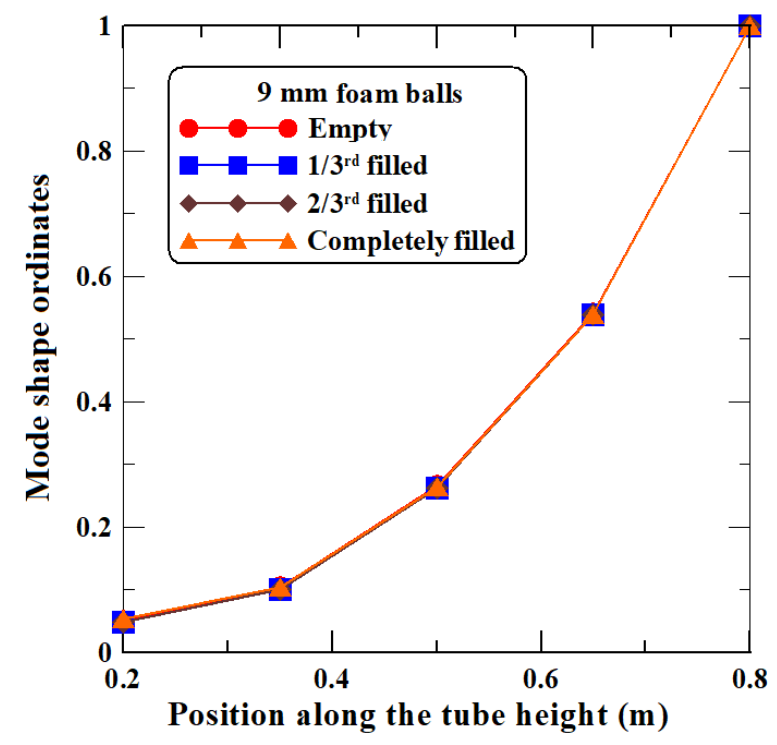

(a)

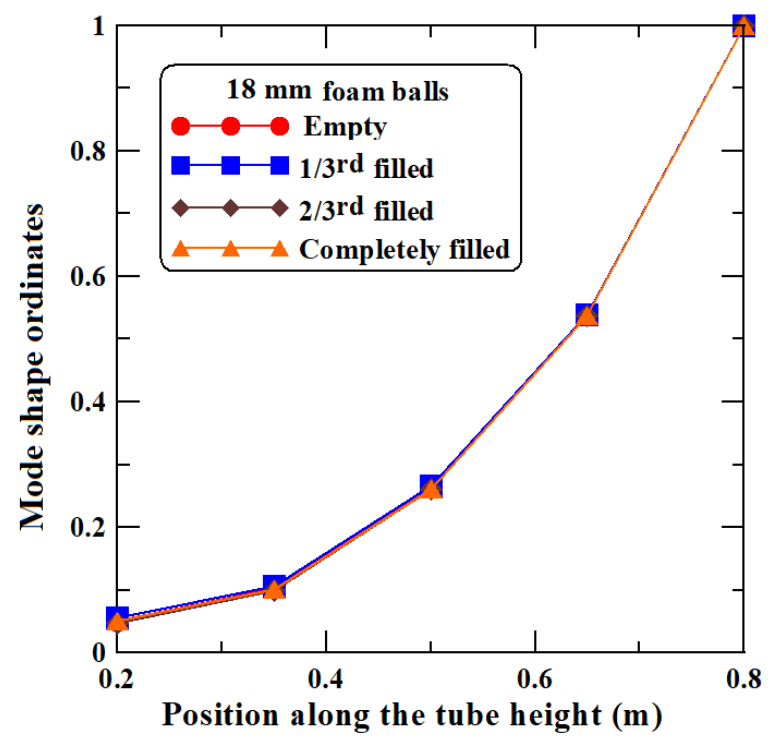

(b)

Figure 8: Fundamental mode shape of foam filled tubes with: (a) $9 \mathrm{~mm}$ and (b) $18 \mathrm{~mm}$ diameter

ity. For plotting, different symbols are used for the different trend lines. The $\mathrm{x}$-axis represents the r.m.s value of base acceleration. From this, it can be noted that the natural frequency of the tube (in empty state) is found to be reduced by almost $5.58 \%$ when the r.m.s excitation level is increased from $0.05 \mathrm{~g}$ to $0.29 \mathrm{~g}$ (i.e., 5.8 times). From Figures $7 \mathrm{a}$ and $7 \mathrm{~b}$, a maximum reduction of $1.18 \%$ and $1.73 \%$ in the fundamental frequency is found when the tube is completely filled with $9 \mathrm{~mm}$ and $18 \mathrm{~mm}$ foam balls (having $0.82 \%$ and $1.05 \%$ of the tube's mass), respectively. Ta- ble 1 shows the The fundamental frequencies of the tubes with empty and foam filled states (with $18 \mathrm{~mm}$ balls) obtained at particular r.m.s base acceleration values of $0.1 \mathrm{~g}$, $0.2 \mathrm{~g}$ and $0.3 \mathrm{~g}$ (using the trend and vertical lines in Figure 7). From the table, a slight reduction of $1.77 \%, 1.48 \%$, and $0.79 \%$ in the fundamental frequency can be noted due to the added mass of balls $(18 \mathrm{~mm}$ ) when subjected to r.m.s base acceleration of $0.1 \mathrm{~g}, 0.2 \mathrm{~g}$, and $0.3 \mathrm{~g}$, respectively. Figures $8 \mathrm{a}$ and $8 \mathrm{~b}$ show the fundamental mode shape of tubes with empty and foam filled states with $9 \mathrm{~mm}$ and $18 \mathrm{~mm}$ 
Table 1: Damping ratio of CFRP empty and foam-filled tubes (with $18 \mathrm{~mm}$ foam balls)

\begin{tabular}{cccccc}
\hline Tube state & $\begin{array}{c}\text { Tube mass } \\
(\mathbf{g m})\end{array}$ & $\begin{array}{c}\text { r.m.s base } \\
\text { acceleration }(\mathbf{g})\end{array}$ & $\begin{array}{c}\text { Natural } \\
\text { frequency }(\mathbf{H z})\end{array}$ & $\begin{array}{c}\text { Damping ratio } \\
(\%)\end{array}$ & $\begin{array}{c}\text { Damping } \\
\text { magnification }\end{array}$ \\
\hline Empty & 400.0 & 0.1 & 18.61 & 1.33 & - \\
$1 / 3^{\text {rd }}$ filled & 401.4 & 0.1 & 18.56 & 1.45 & $1.09 x$ \\
$2 / 3^{\text {rd }}$ filled & 402.8 & 0.1 & 18.41 & 1.70 & $1.28 \mathrm{x}$ \\
Completely filled & 404.2 & 0.1 & 18.28 & 1.84 & $\mathbf{1 . 3 8 x}$ \\
\hline Empty & 400.0 & 0.2 & 18.20 & 2.11 & \\
$1 / 3^{\text {rd }}$ filled & 401.4 & 0.2 & 18.12 & 2.61 & $1.24 x$ \\
$2 / 3^{\text {rd }}$ filled & 402.8 & 0.2 & 18.03 & 2.70 & $1.28 x$ \\
Completely filled & 404.2 & 0.2 & 17.93 & 2.85 & $\mathbf{1 . 3 5 x}$ \\
\hline Empty & 400.0 & 0.3 & 17.76 & 2.83 & \\
$1 / 3^{\text {rd }}$ filled & 401.4 & 0.3 & 17.69 & 3.75 & $1.33 x$ \\
$2 / 3^{\text {rd }}$ filled & 402.8 & 0.3 & 17.65 & 3.75 & $1.33 x$ \\
Completely filled & 404.2 & 0.3 & 17.62 & 4.00 & $\mathbf{1 . 4 1 x}$ \\
\hline
\end{tabular}

diameter foam balls, respectively. From this, the effect of foam filling on mode shape of the tube is found to be negligible for all empty and filled states.

\section{Damping ratio}

Figure 9 shows the damping ratio of the fundamental mode for the empty tube under varying excitation levels. The $x$-axis of the figure represents the r.m.s value of base acceleration measured using the accelerometer attached at the base. One can observed that the damping ratio is signif-

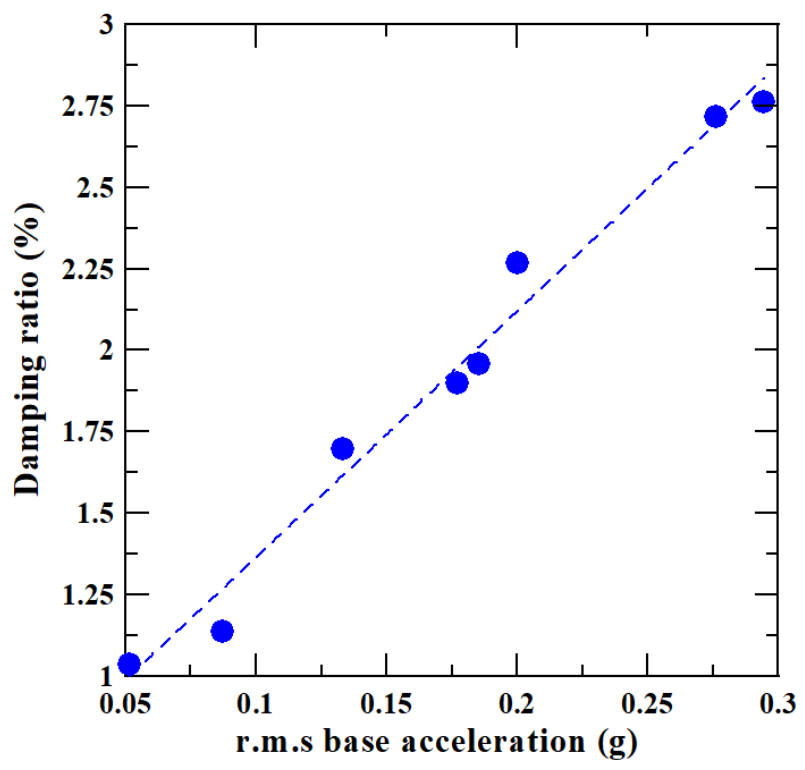

Figure 9: Damping ratio of the tube subjected to varying excitation level icantly increased from $1.04 \%$ to $2.76 \%$ (i.e., by 2.65 times) when the r.m.s base acceleration is increased from $0.05 \mathrm{~g}$ to $0.29 \mathrm{~g}$ (i.e., 5.8 times) due to high amplitude-dependent damping at higher level of excitation [20].

Similarly, the damping ratio of foam filled tube in $1 / 3^{\text {rd }}, 2 / 3^{\text {rd }}$ and completely filled states are evaluated. Figures $10 \mathrm{a}$ and $10 \mathrm{~b}$ show the damping ratio for tubes with empty and foam filled states with $9 \mathrm{~mm}$ and $18 \mathrm{~mm}$ diameter foam balls when subjected to varying excitation levels, respectively. The $\mathrm{x}$-axis of the figure represents the r.m.s value of input base acceleration. To understand the influence of foam balls on damping ratio, a linear trend is fitted. From Figure 10a, one can observe almost similar values of damping ratio of the tube for empty and different foam filled states with $9 \mathrm{~mm}$ diameter ball. From Figure 10b, one can note the significant enhancement in damping ratio of the empty tube and different foam filled tubes, especially, when it is completely filled with $18 \mathrm{~mm}$ diameter foam balls and subjected to higher level of excitation. The enhancement in damping for $18 \mathrm{~mm}$ balls is due to the energy dissipation (i) by collisions and friction between the balls and (ii) collision of the ball with walls of the tube (because of the gap between the circular balls and the square tube). The enhancement in damping for $9 \mathrm{~mm}$ balls is minimal due to lesser effective area available for the movement and sliding of the balls because of its compact packing (see Figure 3).

Table 1 depicts the damping ratios and damping magnification factors for the tube with empty and foam filled states (with $18 \mathrm{~mm}$ diameter balls) for r.m.s excitation levels of $0.1 \mathrm{~g}, 0.2 \mathrm{~g}$, and $0.3 \mathrm{~g}$ (obtained using the linear fitted trend in Figure 10b). The damping magnification is defined herein as a factor of the damping ratios of the foam filled 


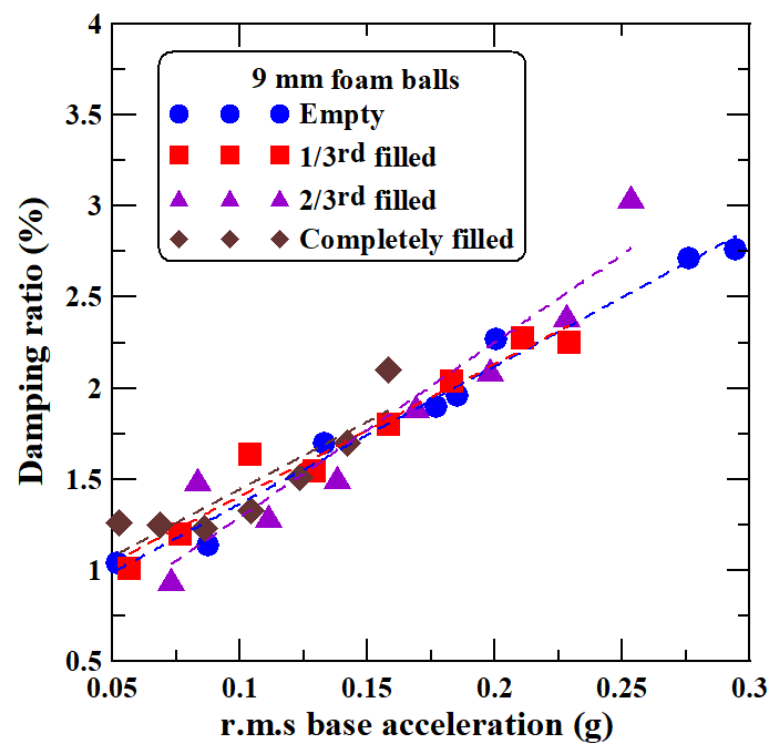

(a)

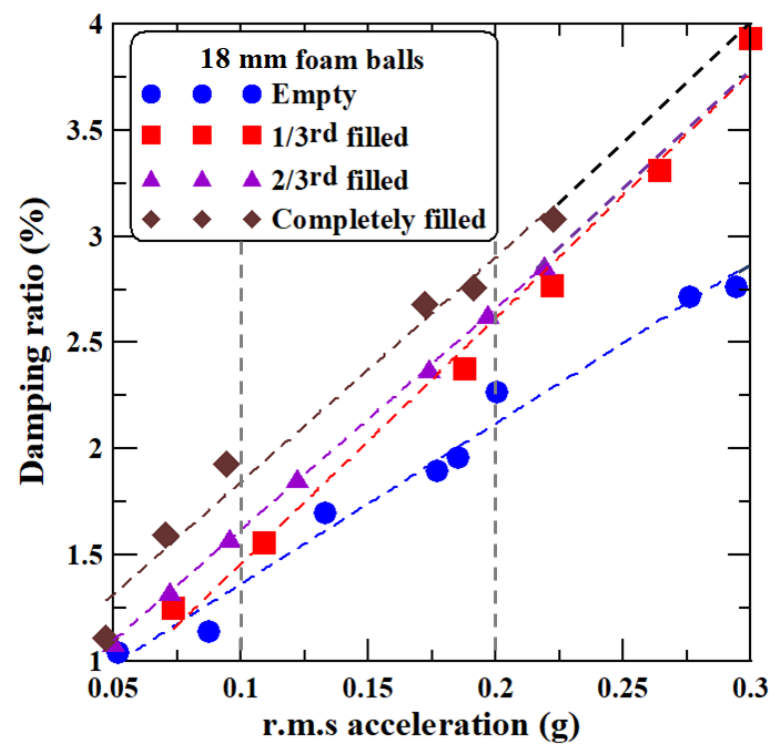

(b)

Figure 10: Damping ratio of empty and foam filled tubes with (a) $9 \mathrm{~mm}$ and (b) $18 \mathrm{~mm}$ diameter foam balls for varying excitation level

state with respect to its value for the empty state. From this table, one can note the higher values of damping magnification factor for tube with foam filled states at higher level of excitation. At higher r.m.s excitation levels of $0.2 \mathrm{~g}$ and $0.3 \mathrm{~g}$, the damping magnification factor can be noted almost similar i.e., $\sim 1.28 \mathrm{x}$ (i.e., times) and 1.33x for one-third and two-third filled states, respectively. The damping ratio is enhanced to $1.41 \mathrm{x}$ for completely foam filled state when subjected to r.m.s base acceleration of $0.3 \mathrm{~g}$. Finally, it may be noted that filling tube with EPS foam fillers depending on its packing configuration (or filler size), enhances the damping ratio significantly without much increase in the mass (i.e., $~ 1 \%$ ).

\section{Conclusion}

In this study, the dynamic behaviour of empty and EPS foam filled CFRP composite tubes is experimentally investigated under varying level of base excitation. The tube is filled with foam balls of different sizes (i.e., $9 \mathrm{~mm}$ and $18 \mathrm{~mm}$ diameter) and for varying depths (i.e., $1 / 3^{\text {rd }}, 2 / 3^{\text {rd }}$ and full). Shake table experiments are performed and accelerometers are mounted at different positions along the tube height and at the base to record the vibration responses. The dynamic characteristics of the tube such as natural frequency, mode shape and damping ratio of the fundamental mode are evaluated. The fundamental frequency of the tube is found to be decreased (by 5.58\%) with increase in the level of excitation (i.e., r.m.s base acceleration from $0.05 \mathrm{~g}$ to $0.29 \mathrm{~g}$ ). The maximum change in the natural frequency of the tube due to foam fillers is found to very small i.e., $1.18 \%$ and $1.73 \%$ for $9 \mathrm{~mm}$ and $18 \mathrm{~mm}$ diameter foam balls, respectively. The mode shape is observed to be same for the empty and filled states (for all cases). For the empty tube, damping ratio is found to be enhanced by 2.65 times when the r.m.s base acceleration is increased from $0.05 \mathrm{~g}$ to $0.29 \mathrm{~g}$ (i.e., 5.8 times). Damping ratio is found to be significantly higher for the tube filled with $18 \mathrm{~mm}$ foam balls owing to dissipation of vibrational energy through friction and impact produced by collision of the balls (with each other and with tube's wall), which is higher for more number of balls in the tube (i.e., complete filled state). The maximum enhancement in damping ratio is noted to be $1.41 \mathrm{x}$ for the completely foam filled case, subjected to r.m.s base acceleration of $0.3 \mathrm{~g}$ when compared with the values corresponding to the empty case.

\section{Acknowledgments}

The authors would like to thank Laboratory technicians and staff of Structural Engineering Laboratory, Indian Institute of Technology Kanpur for their help and guidance during the work. This work was partially supported by Indian Space Research Organization (ISRO) through ISROIITK Space Technology Cell. 


\section{References}

[1] Tu Y., Wang G. Damping Parameter Identification and Study of Metal Foam Filled Steel Tube. J. of Mat. in Civil Eng., ASCE, 2010, 22, 397-402.

[2] Strano M., Marra A., Mussi V., Goletti M., Bocher P. Endurance of Damping Properties of Foam-Filled Tubes. Materials, 2015, 8, 4061-4079.

[3] Liu Q., Mo Z., Wu Y., Ma J., Tsui G. C. P., Hui D. Crush response of CFRP square tube filled with aluminum honeycombs. Compos.: Part B., 2016, 98, 406-414.

[4] Jamil A., Guan Z. W., Cantwell W. J. The static and dynamic response of CFRP tube reinforced polyurethane. Compos.: Part B., 2017, 161, 85-92.

[5] Hussein R. D., Ruan D., Lu G., Guillow S., Yoon J. W. Crushing response of square aluminium tubes filled with polyurethane foam and aluminium honeycomb. Thin-Walled Struct., 2017, 110, 140-154.

[6] Zhou J., Guan Z. W., Cantwell W. J. The energy-absorbing behaviour of composite tube-reinforced foams. Compos.: Part B, 2018, 139, 227-237.

[7] Hussein R. D., Ruan D., Lu G., Thomson R. An energy dissipating mechanism for crushing square aluminium/CFRP tubes. Compos. Struct., 2018, 183, 643-653.

[8] Landro L. Di., Sala G., Olivieri D. Deformation mechanisms and energy absorption of polystyrene foams for protective helmets. Poly. Test., 2002, 21, 217-228.

[9] Krundaeva A., Bruyne G. D., Gagliardi F., Paepegem W. V. Dynamic compressive strength and crushing properties of expanded polystyrene foam for different strain rates and different temperatures. Poly. Test., 2016, 55, 61-68.

[10] Xu P., Yu Y., Li K., Wu X. SHPB experiment research on dynamic property of expanded polystyrene foam. Poly. Test., 2018, 69, 431-436.
[11] Horvath J. Expanded polystyrene (EPS) geofoam: an introduction to material behaviour. Geotext. Geomembr., 1994, 55, 263-280.

[12] Baumeister J., Monno M., Goletti M., Mussi V., Weise J. Dynamic Behavior of Hybrid APM (Advanced Pore Morphology Foam) and Aluminum Foam Filled Structures. Metals, 2012, 2, 211-218.

[13] Duarte I., Vesenjak M., Opara L. K. Dynamic and quasi-static bending behaviour of thin-walled aluminium tubes filled with aluminium foam. Compos. Struct., 2014, 109, 48-56.

[14] Taherishargh M., Vesenjak M., Belova I. V., Opara L. K., Murch G. E., Fiedlera $T$. In situ manufacturing and mechanical properties of syntactic foam filled tubes. Mater. and Des., 2016, 99, 356-368.

[15] TScott-Emuakpor O., George T., Runyon B., Beck J., Sheridan L., Holycross C. O'Hara R. Sustainability Study of Inherent Damping in Additively Manufactured Nickel Alloy. AIAA J., 2018, 1-6.

[16] Caicedo J. M., Dyke S.J.,Johnson E.A. Natural Excitation Technique and Eigensystem Realization Algorithm for Phase I of the IASC-ASCE Benchmark Problem: Simulated Data. J. of Eng. Mech., ASCE, 2004, 49, 50-60.

[17] Caicedo J. M. Practical Guidelines for the Natural Excitation Technique (NExT) and the Eigensystem Realization Algotitham (ERA) for Modal Identification using Ambient Vibration. Exp. Tech., 2011, 35, 52-58.

[18] Juang J.N., Pappa R.S. An Eigensystem Realization Algorithm for Modal Parameter Identification and Model Reduction. J. of Guid. Cont. and Dyn., 1985, 8, 620-627.

[19] Minwoo Chang S.M., Shamim N. Pakzad A.M. Modified Natural Excitation Technique for Stochastic Modal Identification. J. of Str. Eng., ASCE, 2013, 139, 1753-1762.

[20] Crandall S.H. The Role of Damping in Vibration Theory. J. of Sou. and Vib., 1970, 11, 3-18. 